International Journal of Biomathematics

Vol. 1, No. 4 (December 2008) 521-523

(C) World Scientific Publishing Company

\title{
AUTHOR INDEX (Volume 1)
}

Cai, L., Li, X. \& Song, X., Modeling and analysis of a harvesting fishery model in a two-patch environment

3 (2008) 287

2 (2008) 171

2 (2008) 197

2 (2008) 179

2 (2008) 147

2 (2008) 121

2 (2008) 225

1 (2008) 1

3 (2008) 267

2 (2008) 239

1 (2008) 65

1 (2008) 107

Dai, B., see Wang, Q.

Ding, X. \& Wang, Y., Positive periodic solution for a gause-type ratio-dependent predator-prey system with diffusion and time delay

Dou, J., A monotoneiterative method for finding periodic solution of an impulsive differential equations and application

Fan, Y.-H., see Wang, L.-L.

Feng, C. \& Huang, Z., Almost periodicity in an impulsive logistic equation with infinite delay

Feng, J. \& Wang, T.-M., A discrimination measure for phylogenetic tree construction

Feng, Z. S., see Ma, S. Q.
3 (2008) 355

2 (2008) 161
Gan, Q., Xu, R. \& Yang, P., Bifurcation analysis for a predator-prey system with prey dispersal and time delay

2 (2008) 209

Georgescu, P., see

Zhang, $\mathrm{H}$

Gui, Z. \& Zhang, J. Periodic solution for neutral delay differential equations model of plankton allelopathy Guo, B.-H., Cai, S.-H. \& Zhu, J.-Q., The birth and death equation of virus spreading

1 (2008) 1

3 (2008) 391

Guo, H., see Song, X.

Haque, M., see Jin, Z.

He, Z.-R., see Luo, Z.

He, Z.-R., Global dynamics of nonlinear two-staged age-dependent populations

Huang, X., Yang, W. \& Li, X., Permanence of a discrete $n$-species Lotka-Volterra type food-chain system with feedback controls and time delays

Huang, Z., see Feng, C. Jiang, H., see Wang, K. Jiao, J. \& Chen, L., Global attractivity of a stage-structure variable coefficients predator-prey system with time delay and impulsive perturbations on predators

2 (2008) 197
4 (2008) 449

2 (2008) 171

3 (2008) 313

4 (2008) 409

2 (2008) 133

3 (2008) 299

3 (2008) 355

1 (2008) 29

Jin, Z., Haque, M. \& Liu,

Q., Pulse vaccination in 
the periodic infection rate SIR epidemic model Jin, Z., see Xue, Y.

Kang, A., see Xue, Y.

Li, S., see Xiong, Z.

Li, X., see Cai, L.

Li, X., see Huang, X.

Li, Z., see Wang, $\mathrm{X}$.

Lian, J.-G. \& Zhang, H.-K., Stability of $T$-periodic solution on the extended simplified Brusselator model

Liu, J., see Zhang, T.

Liu, Q., see Jin, Z.

Liu, S., see Pei, Y.

Liu, Y. \& Cui, J.-A., The impact of media coverage on the dynamics of infectious disease

Lu, Q. S., see Ma, S. Q.

Lu, Z. \& Wu, J., Global stability of a chemostat model with delayed response in growth and a lethal external inhibitor

Luo, J., Yuan, S. \& Zhang, W., Competition between two microorganisms in the chemostat with general variable yields and general growth rates

Luo, Z. \& He, Z.-R., Optimal harvesting problem for an age-dependent n-dimensional competing system with diffusion

Ma, S. Q., Lu, Q. S., Wang, Q. Y. \& Feng, Z. S., Effects of time delay on two neurons interaction Morris-Lecar model

Meng, X. \& Chen, L., Permanence and global stability in an impulsive Lotka-Volterra $n$-species competitive system with both discrete delays and continuous delays

Meng, X. \& Zhang, T., Global dynamic behaviors of a two-dimensional
2 (2008) 179

3 (2008) 327

3 (2008) 327

3 (2008) 361

3 (2008) 287

3 (2008) 299

1 (2008) 95

1 (2008) 19

1 (2008) 45

4 (2008) 409

2 (2008) 147

1 (2008) 65

2 (2008) 161

4 (2008) 503

4 (2008) 463

2 (2008) 133

2 (2008) 161
4 (2008) 409 integral-differential almost periodic system with infinite delays and discrete delays

4 (2008) 487

Mukherjee, D., Effect of delay on two competing organism in a polluted environment

4 (2008) 475

Pei, Y., Liu, S., Chen, L. \& Wang, C., Two different vaccination strategies in an SIR epidemic model with saturated infectious force

Song, G., Estimates of solutions of impulsive parabolic equations and application

2 (2008) 257

Song, X. \& Guo, H., Global stability of a

stage-structured predator-prey system

Song, X., see Cai, L.

Sun, S. \& Chen, L., Permanence and complexity of the eco-epidemiological model with impulsive perturbation

2 (2008) 121

Tan, Y., Tao, F. \& Chen, L., Dynamics of a nonautonomous system with impulsive output

Tang, S., A comparison investigation of the simplest models of circadian rhythms

Tao, F., see Tan, Y. Tao, Y., see Wang, X. Teng, Z., see Wang, K. Teng, Z., see Zhang, T. Wang, C., see Pei, Y. Wang, K., Teng, Z. \& Jiang, H., On the permanence for $n$-species non-autonomous Lotka-Volterra competitive system with infinite delays and feedback controls 1 (2008) 29
1 (2008) 75

2 (2008) 225

4 (2008) 443

1 (2008) 29

1 (2008) 45

2 (2008) 147

Wang, L.-L. \& Fan, Y.-H., Permanence for a discrete Nicholson's blowflies model with 
feedback control

and delay

Wang, Q. Y., see Ma, S. Q.

Wang, Q. \& Dai, B.,

Existence of positive

periodic solutions for

neutral population model with delays

Wang, T.-M., see Feng, J.

Wang, X. \& Li, Z., Globally dynamical behaviors

for discrete

Lasota-Wazewska

model with several delays

and almost periodic

coefficients

Wang, X. \& Tao, Y., Lyapunov function and global properties of virus dynamics with CTL immune response

Wang, Y., see Ding, $\mathrm{X}$.

$\mathrm{Wu}$, J., see Lu, Z.

Xie, J., see Zou, W.

Xiong, Z., Xue, Y. \& Li, S., $A$ food chain system with Holling IV functional responses and impulsive effect

Xiong, Z., see Zou, W.

Xiuxiang, Y. \& Chunrong, $\mathrm{X} .$, An SIQS infection model with nonlinear and isolation

$\mathrm{Xu}, \mathrm{R}$., see Gan, Q.

Xue, Y., Kang, A. \& Jin, Z., The existence of
1 (2008) 107

4 (2008) 433

2 (2008) 161

3 (2008) 401

1 (2008) 95

4 (2008) 443

3 (2008) 339

4 (2008) 503

3 (2008) 377

3 (2008) 361

3 (2008) 377

2 (2008) 239

2 (2008) 209 positive periodic

solutions of an

eco-epidemic model with

impulsive birth

Xue, Y., see Xiong, Z.

Yang, P., see Gan, Q.

Yang, W., see Huang, X.

Yuan, S., see Luo, J.

Zhang, H. \& Chen, L., A model for two species with stage structure and feedback control

Zhang, H., Georgescu, P. \& Chen, L., An impulsive predator-prey system with BeddingtonDeangelis functional response and time delay

Zhang, H.-K., see Lian, J.-G.

3 (2008) 327

3 (2008) 361

2 (2008) 209

3 (2008) 299

4 (2008) 463

Zhang, J., see Gui, Z.

Zhang, T., Liu, J. \& Teng, Z., Differential susceptibility time-dependent SIR epidemic model

1 (2008) 45

Zhang, T., see Meng, X.

Zhang, W., see Luo, J.

4 (2008) 487

4 (2008) 463

2 (2008) 171

Zhu, J.-Q., see Guo, B.-H.

Zou, W., Xie, J. \& Xiong, Z., Stability and Hopf bifurcation for an eco-epidemiology model with Holling-III

functional response and delays
3 (2008) 267

1 (2008) 1

1 (2008) 19

3 (2008) 391 